Technical Note

\title{
Creating a Field-Wide Forage Canopy Model Using UAVs and Photogrammetry Processing
}

\author{
Cameron Minch, Joseph Dvorak* $*$, Josh Jackson and Stuart Tucker Sheffield
}

Department of Biosystems and Agricultural Engineering, University of Kentucky, Lexington, KY 40546, USA; cameronlmagolan@uky.edu (C.M.); joshjackson@uky.edu (J.J.); st.sheffield@uky.edu (S.T.S.)

* Correspondence: joe.dvorak@uky.edu

check for

updates

Citation: Minch, C.; Dvorak, J.; Jackson, J.; Sheffield, S.T. Creating a Field-Wide Forage Canopy Model Using UAVs and Photogrammetry Processing. Remote Sens. 2021, 13, 2487. https://doi.org/10.3390/ rs13132487

Academic Editors: Mehdi Hosseini, Ritvik Sahajpal, Hannah Kerner and Magaly Koch

Received: 9 April 2021

Accepted: 18 June 2021

Published: 25 June 2021

Publisher's Note: MDPI stays neutral with regard to jurisdictional claims in published maps and institutional affiliations.

Copyright: (c) 2021 by the authors. Licensee MDPI, Basel, Switzerland. This article is an open access article distributed under the terms and conditions of the Creative Commons Attribution (CC BY) license (https:/ / creativecommons.org/licenses/by/ $4.0 /)$.

\begin{abstract}
Alfalfa canopy structure reveals useful information for managing this forage crop, but manual measurements are impractical at field-scale. Photogrammetry processing with images from Unmanned Aerial Vehicles (UAVs) can create a field-wide three-dimensional model of the crop canopy. The goal of this study was to determine the appropriate flight parameters for the UAV that would enable reliable generation of canopy models at all stages of alfalfa growth. Flights were conducted over two separate fields on four different dates using three different flight parameters. This provided a total of 24 flights. The flight parameters considered were the following: $30 \mathrm{~m}$ altitude with $90^{\circ}$ camera gimbal angle, $50 \mathrm{~m}$ altitude with $90^{\circ}$ camera gimbal angle, and $50 \mathrm{~m}$ altitude with $75^{\circ}$ camera gimbal angle. A total of 32 three-dimensional canopy models were created using photogrammetry. Images from each of the 24 flights were used to create 24 separate models and images from multiple flights were combined to create an additional eight models. The models were analyzed based on Model Ground Sampling Distance (GSD), Model Root Mean Square Error (RMSE), and camera calibration difference. Of the 32 attempted models, 30 or $94 \%$ were judged acceptable. The models were then used to estimate alfalfa yield and the best yield estimates occurred with flights at a $50 \mathrm{~m}$ altitude with a $75^{\circ}$ camera gimbal angle; therefore, these flight parameters are suggested for the most consistent results.
\end{abstract}

Keywords: forage canopy; photogrammetry; three-dimensional model; UAV

\section{Introduction}

Alfalfa was the third most valuable field crop in the United States in 2017 and 2018 [1,2]. However, unlike other top field crops, alfalfa is a forage primarily grown for its biomass. As a perennial, multiple harvests per year are produced over multiple years. Alfalfa's yield in any given harvest is determined by the height and density of the plant canopy [3]. Additionally, the nutritive value is a critical factor in the quality of the harvested biomass [4,5]. In alfalfa, there is a tradeoff between nutritive value and yield [6]. As the plant matures and grows taller, which increases yield, the concentration of less digestible components, such as lignin, increases and the nutritive value decreases $[7,8]$. The optimal relationship varies and is affected by location, enterprise management strategies, markets, anticipated end uses, weather, and climate factors unique to every farm and every harvest [9]. Furthermore, alfalfa stands weaken and thin over time and cannot be reseeded. Therefore, another unique decision in growing alfalfa is when to destroy the remaining stand and rotate into other crops. Alfalfa producers need to be aware of the state of the crop to select harvest times and crop rotation schedules that optimize the value to their enterprise [9]. All these considerations are required on top of monitoring for diseases, weeds, and other pest issues in order to deploy appropriate mitigation strategies that are just as important in alfalfa as in any field crop. The structure of the alfalfa canopy is directly related to many important production factors such as yield, quality, stand health, and pest control [10-12]. A three dimensional (3D) model of the physical structure of the alfalfa canopy can be used to 
determine the nutritive value and yield of an alfalfa crop while it is still growing in the field [13].

Unmanned Aerial Vehicles (UAVs) have gained much attention for their potential application as rapid sensing platforms in agriculture. They have proven useful in monitoring soybean disease [14], plant pests in vineyards [15], and crop condition in sorghum [16]. Furthermore, UAVs can also measure the phenotype of plants in breeding programs for various crops from tomatoes [17], wheat [18], and sorghum [19]. Pre-harvest yield has been estimated in cotton $[20,21]$. Sensors on the UAV platforms have also been used to estimate the biomass of barley for fertilizer optimization [22] and the biomass of wheat for crop monitoring and yield predictions [23,24].

All of these studies used photogrammetry to combine the large number of visual or hyperspectral images taken by the UAVs into a single output. In most cases, this was a twodimensional visual light and/or hyperspectral orthomosaic of the field. Photogrammetry can also be used to create three dimensional (3D) models of objects or surfaces captured in the UAV images based on Structure from Motion techniques [25]. Obtaining good data from UAVs requires the proper selection of many variables that control flight, image capture, mission layout, and photogrammetry processing [25] but these are dependent on the characteristics of the application.

Several research groups have attempted to determine the appropriate parameters for various applications. In order to create standard orthomosaics for agricultural applications, Gauci et al. [26] found that flights at altitudes of both $75 \mathrm{~m}$ and $120 \mathrm{~m}$ provided sufficient horizonal accuracy. By contrast, Mesas-Carrascosa et al. [27] suggest flying at no more than $60 \mathrm{~m}$ when creating orthomosaic multispectral images of agricultural fields. Research has also produced differing results when the goal is to produce a 3D model rather than an orthomosaic. Seifert et al. [28] suggest flying as low as possible-as low as their minimum tested altitude of $25 \mathrm{~m}$-when trying to capture 3D models of forest canopies. At even lower altitudes, Nakano et al. [29] found that an altitude of $10 \mathrm{~m}$ was not usable because of plant movement caused by propeller downwash, but that flights at $20 \mathrm{~m}$ and $30 \mathrm{~m}$ altitudes provided the detail they desired. For capturing archeological sites [30] and creating 3D models of buildings [31], acceptable results were found at flight altitudes between $30 \mathrm{~m}$ and $80 \mathrm{~m}$. However, this research also notes that it is necessary to consider the desired uses for the data since operations at lower altitudes had higher accuracy but significantly longer flight times. Based on a detailed analysis of the tradeoffs, Torres-Sánchez et al. [32] suggested flying at an altitude of $100 \mathrm{~m}$ when creating 3D models of olive trees to minimize flight time. These studies focused on a variety of different applications and therefore suggest flights with various altitudes and other parameters. One set of flight parameter has not proven optimal for every application.

The prior studies that focused on using UAVs for estimating plant biomass or yield did not report flight tests on what effect using different flight parameters would have on their results. All flights were conducted at heights above ground level of $50 \mathrm{~m}[20,22,24]$, $45 \mathrm{~m}$ [21], or $30 \mathrm{~m}$ [23]. Nadir orientations (pointing directly down or $90^{\circ}$ gimbal angle) were either explicitly or implicitly described for camera orientation in these studies. In [23], the researchers down sampled the images and concluded that they could have flown at $240 \mathrm{~m}$ above ground level, but this was not verified through flight campaigns. While studies have concluded that crop height models derived from photogrammetry and UAVacquired images can produce useful information, there has not been consistent testing on the effects that different flight parameters have on those results.

During our projects using UAVs to monitor alfalfa, some of the most frequent questionsperhaps even as common as the research results-have been directed to our success rate for creating 3D models of the alfalfa canopy and the flight, mission, and photogrammetry settings that provided that level of success. None of the previously mentioned studies of flight parameters have focused on alfalfa or forage crops. Current manual field measurements for estimating nutritive quality require determining canopy heights with $2.5 \mathrm{~cm}$ resolution [11] and achieving this level of detail in the canopy model calls for lower flight 
altitudes. Alfalfa can be particularly challenging since once the canopy closes, the field appears as a consistent green surface that undulates in windy conditions. This type of surface and the lower flight altitudes limit the unique and consistent features that the photogrammetry model creation process requires in order to produce useful models. In these challenging conditions, the process can simply fail or produce unusable models with many odd artifacts and multiple ground surfaces (Figure 1).

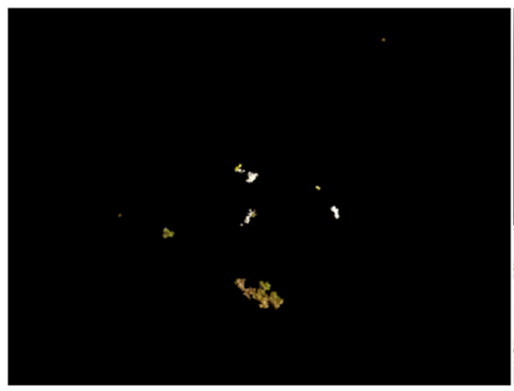

(a)

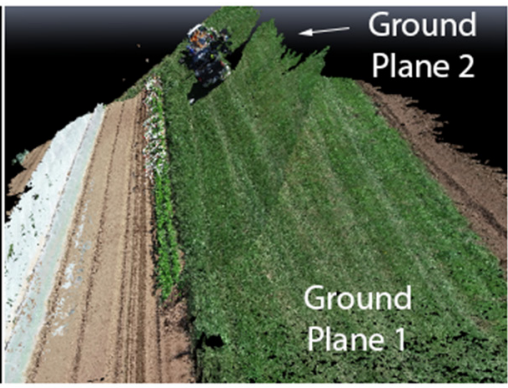

(b)

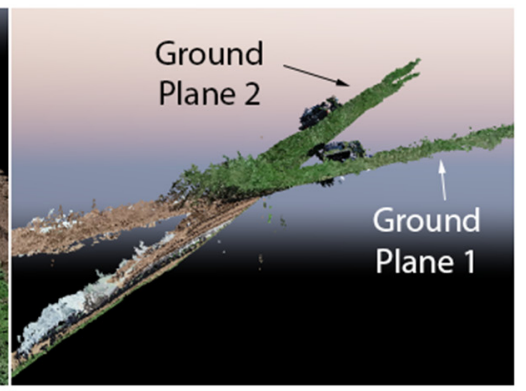

(c)

Figure 1. Failed models from the photogrammetry process: (a) A model that generated only a few scattered points; (b) a model that generated two intersecting ground planes; (c) a side view of the intersecting ground planes in (b).

The challenges in creating alfalfa canopy models and the questions from others motivated the goal of this study, which was to develop and compare alfalfa canopy models derived from UAV imagery with different flight parameters (altitude and camera angle). Our initial motivation was to identify an efficient set of flight parameters that would reliably create successful models to enable the determination of canopy heights within the $2.5 \mathrm{~cm}$ resolution used in current manual field measurements [11]. However, other applications and uses of the 3D forage canopy models may call for different accuracy levels. One application of these models is to use them to estimate crop parameters such as yield. Therefore, to provide an illustration of the effects of these differences in 3D canopy creation, these canopies were used with previously developed models to estimate yield based on 3D canopy point clouds. In this study, our objective was to conduct an assessment on the ability to successfully create 3D canopy models using various flight parameters. Additionally, we wanted to ensure that the suggested methods work throughout the entire alfalfa regrowth process - from the initial sparse plant crowns to the fully closed canopies before harvest. The results of this investigation will help engineers and researchers utilizing 3D plant canopy models in the identification of the most useful and efficient methods to successfully create these models.

\section{Materials and Methods}

\subsection{Experiment Fields}

In this study, we used two alfalfa fields, Field 1 and Field 2 (Figure 2), which are located at the University of Kentucky's North Farm with the approximate centroid of each field located at $(38.128688,-84.509497)$ and $(38.118587,-84.509612)$, respectively. The soil types in Field 1 were Armour silt loam, Egam silt loam, and Huntington silt loam. Field 2 consisted of Armour silt loam, Huntington silt loam, and Bluegrass-Maury silt loam. Data collection occurred from 17 May 2019 to 4 June 2019 with four separate data collection days. The first alfalfa cutting in the field for the 2019 growing season was cut on 7 May 2019 with a John Deere 630 Discbine mower (Moline, Illinois) and collected as haylage on 9 May 2019. This data collection period covered the alfalfa growth period between the first and second cuttings of the year. The second cutting occurred several days after data collection ended. Maturity levels ranged from 0 to 5 using the maturity stage evaluation scale from Kalu and Fick [33]. The alfalfa in Field 1 was a reduced lignin and glyphosate resistant variety, Ameristand 400 HVXRR, and the alfalfa in Field 2 was a glyphosate resistant variety, Allied 428RR. One herbicide spray application was performed during the data collection period, 
on 21 May 2019. Weed, insect, and disease pressure were manually evaluated at 10 points ( $1 \mathrm{~m}^{2}$ sampling quadrats) in each field on each of the four separate data collection days. After performing the drone flights on each day, the alfalfa in each sampling quadrat was hand harvested, weighed, and dried to determine the dry matter yield for each quadrat.

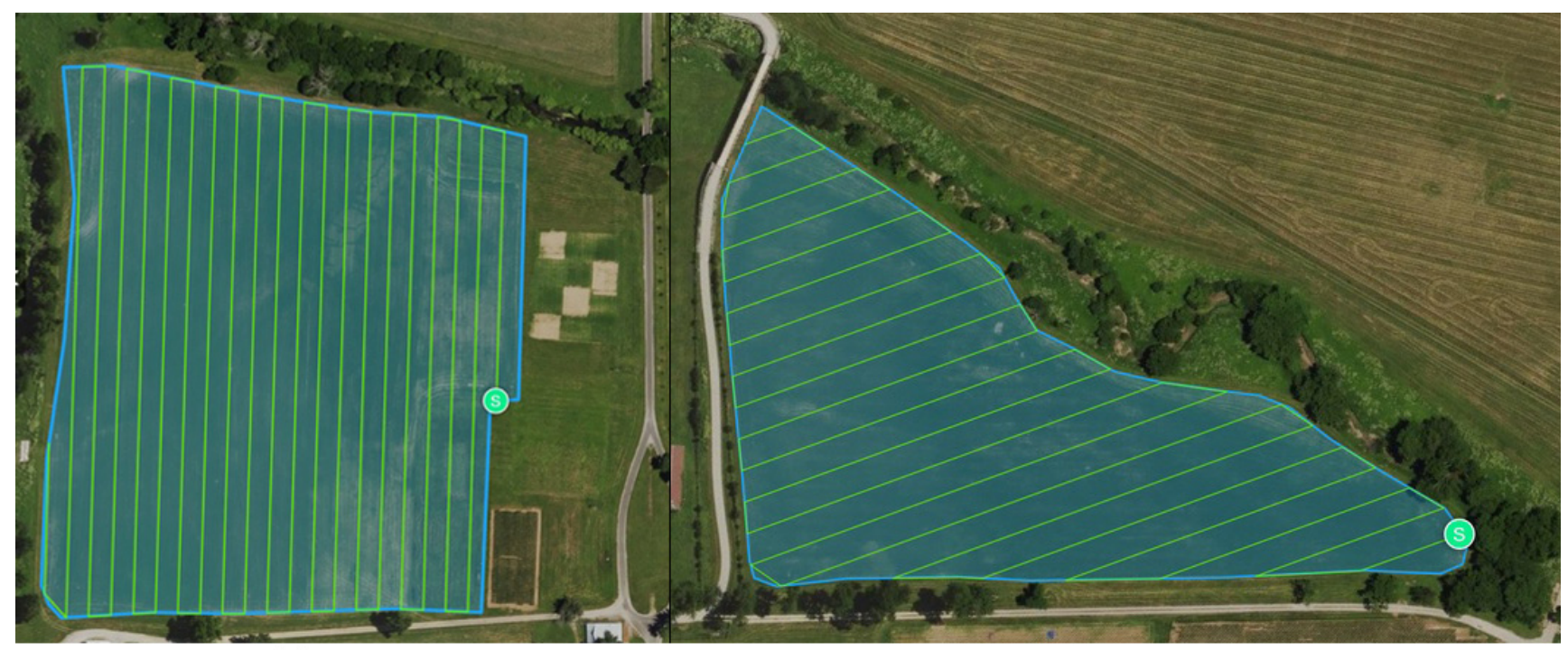

(a)

(b)

Figure 2. Field 1 (a) and Field 2 (b) outlined in blue. The green lines show the UAV path when following a mission to cover the entire field. The " $\mathrm{S}$ " indicates the starting point of the mission.

\section{Field Conditions}

Weed pressure was low throughout the sampling period in both fields, with nearly all measured locations having less than $5 \%$ weed presence and only a minority in the $5 \%$ to $20 \%$ range. Insect and disease pressure were initially similar to weed pressure, with most locations possessing less than $5 \%$ of plants exhibiting damage from insects or disease. However, insect and disease pressure increased during the data collection period and by 4 June 2019 , more locations had between $5 \%$ and $20 \%$ of plants showing damage from these sources.

\subsection{Data Collection Process}

\subsubsection{Ground Control Points}

On each data collection day, the first step was to record Ground Control Points (GCPs) and we also conducted our maturity, weed, insect, and disease evaluations throughout the field. The GCPs were the brightly painted corners of sampling quadrats (10 per field and 20 on each date), which were distributed in the field. These were rigid, located above the alfalfa canopy, and easily identifiable, which rendered them good GCPs. The GCPs were located using a Trimble 5800 receiver (Trimble Inc., Sunnyvale, CA, USA) and the Lefebure NTRIP Client (Cedar Rapids, Iowa), which provided RTK corrections from the Kentucky Continuous Operated Reference Stations (KYCORS) network.

\subsubsection{Flights}

After the GCPs were collected, three flight missions using different flight parameters were flown on each field using a DJI Phantom 4 Pro UAV (Shenzhen, China) for a total of six flights per day and 24 total unique flights. The Phantom 4 Pro has an integrated 20-megapixel $2.54 \mathrm{~cm}$ CMOS visible camera mounted on a gimbal. The camera lens has an $84^{\circ}$ field of view and an $8.8 \mathrm{~mm}$ focal length. The missions were developed using DJI Go and DJI GS Pro Mobile applications. All missions were set to have the images captured at equal intervals perpendicular to the main path without stopping. The images had a front 
overlap of $85 \%$ and a side overlap of $75 \%$. The flight parameters varied based on elevation and gimbal angle (Table 1). Altering elevation and gimbal angle changed the resolution and the mission planning app automatically adjusted flight speed to ensure image quality (also shown in Table 1). In order to distinguish between these flight parameters (FP), they will hereafter be referred to by the elevation and gimbal angle as the $50-90^{\circ}, 50-75^{\circ}$, and $30-90^{\circ}$ flight parameters.

Table 1. The flight parameters for the three types of missions.

\begin{tabular}{|c|c|c|c|}
\hline & $\begin{array}{c}\text { Flight Parameters } 1 \\
\left(50-90^{\circ} \text { FP }\right)\end{array}$ & $\begin{array}{c}\text { Flight Parameters } 2 \\
\left(50-75^{\circ} \text { FP }\right)\end{array}$ & $\begin{array}{c}\text { Flight Parameters } 3 \\
\left(30-90^{\circ} \text { FP }\right)\end{array}$ \\
\hline Elevation (m) & 50.0 & 50.0 & 30.0 \\
\hline Speed $\left(\mathrm{m} \mathrm{s}^{-1}\right)$ & 5.70 & 5.70 & 3.30 \\
\hline Gimbal Angle a & $-90.0^{\circ}$ & $-75.0^{\circ}$ & $-90.0^{\circ}$ \\
\hline Resolution (cm px $\left.{ }^{-1}\right)$ & 1.40 & 2.20 & 0.80 \\
\hline
\end{tabular}

a Gimbal angle was measured from the horizontal.

Missions providing complete field coverage took over $21 \mathrm{~min}$ for Field 1 (7.02 ha) and over $10 \mathrm{~min}$ for Field 2 (3.09 ha), even when using the highest speed 50-90 flight parameters (Table 2). However, the GCPs (based on equipment placement for another experiment) were all located in a smaller region of each field. In order to reduce the flight time, images captured, and the resulting processing time, the mission areas were reduced from 7.02 ha to 1.3 ha for Field 1 and from 3.09 ha to 2.02 ha for Field 2 (Figure 3). Some of the missions flown at $50 \mathrm{~m}$ still covered the entire field area to provide full field models, but most flights were of the smaller partial field region. Whether or not a particular flight (day/field/flight parameters) covered the entire field or part of the field is indicated in the results. For this analysis, flight routes and mission durations are dependent on both flight elevation and gimbal angle. The mission duration over the partial subsection of Field 1 at $50 \mathrm{~m}$ did increase by $45 \%$, from $2 \min 52 \mathrm{~s}$ to $4 \min 9 \mathrm{~s}$ when the gimbal angle changed from $75^{\circ}$ to $90^{\circ}$, even though the covered areas and flight elevation remained the same. Changes to the flight route enabled by the difference in gimbal angle provided the time reduction.

Table 2. Mission characteristics when operating with each set of flight parameters in each field.

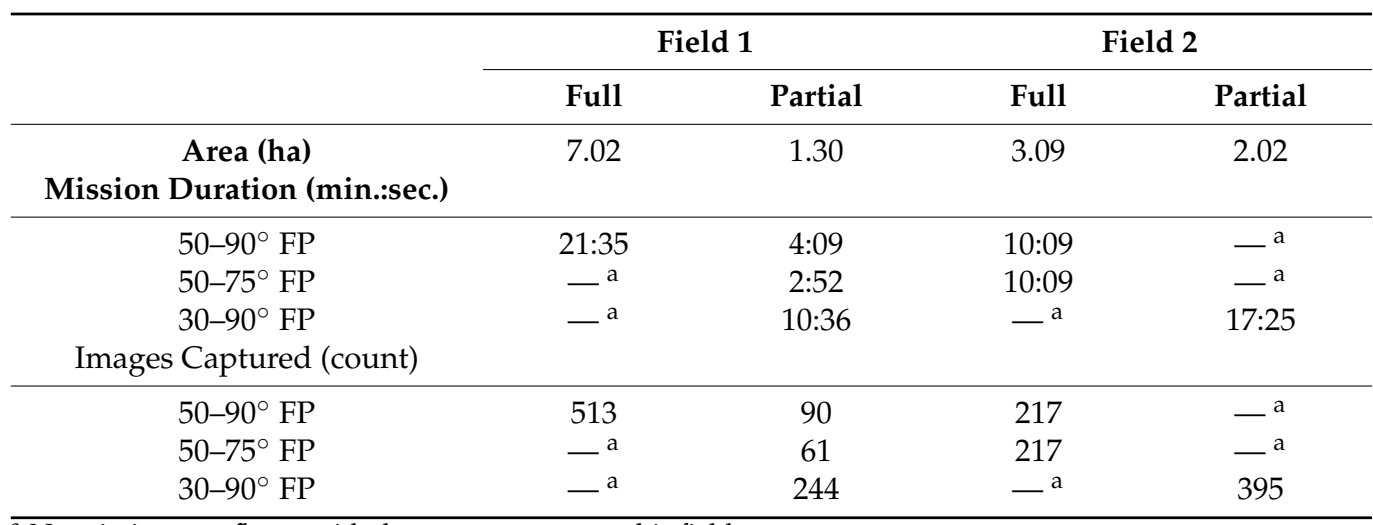

a No mission was flown with these parameters on this field. 


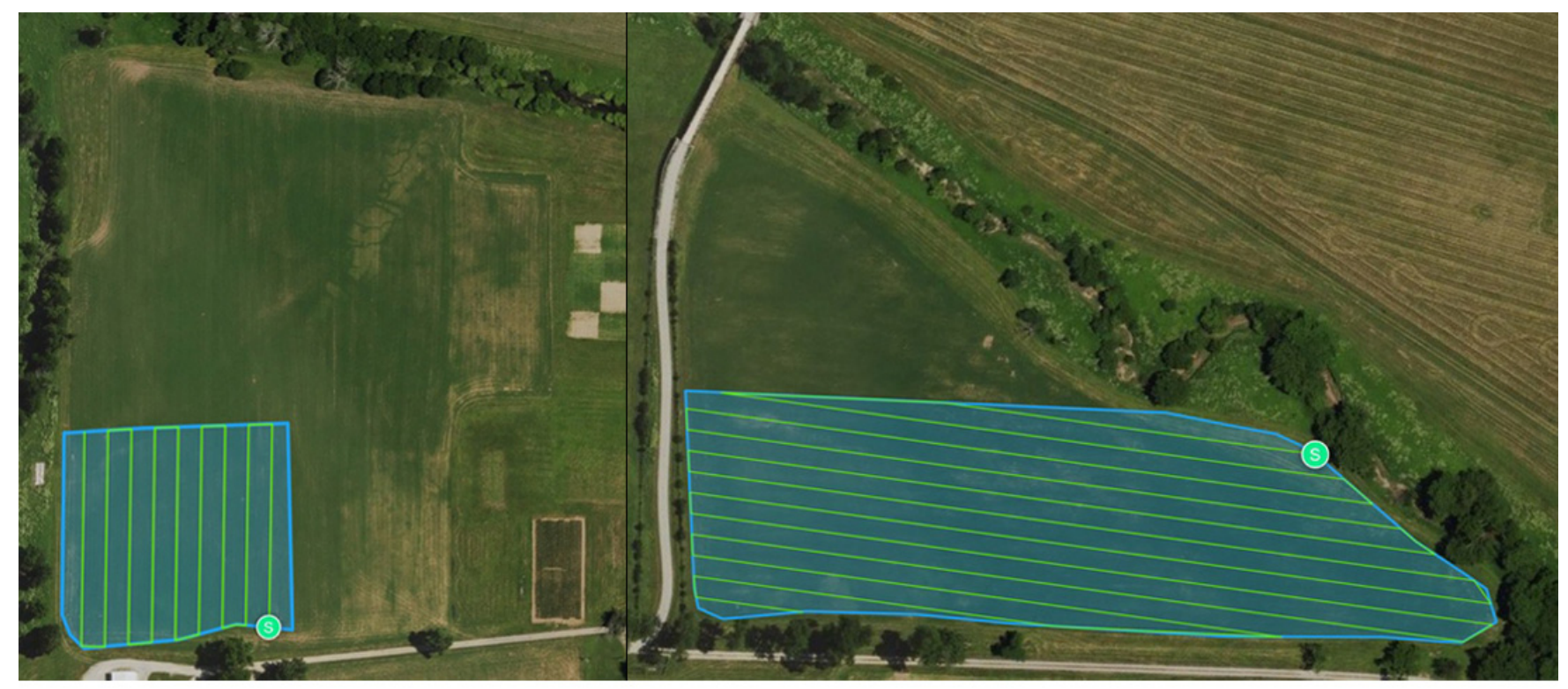

(a)

(b)

Figure 3. Field 1 (a) partial field layout with the route for the $50-90^{\circ}$ flight parameters and Field 2 (b) partial field layout with the route for the $30-90^{\circ}$ flight parameters. The "S" indicates the starting point of the mission.

After flying the three missions that provided scans of the field, a fourth mission was conducted that flew around each of the sampling quadrats individually. The UAV was flown in a circle with a diameter of between $10 \mathrm{~m}$ and $20 \mathrm{~m}$ around the quadrat at a height of approximately $10 \mathrm{~m}$. The UAV flew this circular route three times around the quadrat with the camera locked onto the quadrat while recording video (30 frames per second, 4 K UHD: $3840 \times 2160$ pixels). This provided imagery of the alfalfa within the quadrat from many different angles at a close distance. During photogrammetry processing, this video was subsampled and every 30th frame was extracted. This provided between 40 and 80 images of each sampling quadrat. For this mission, photogrammetry processing was performed individually for each quadrat using the images extracted from the videos. Ground control points were not used since each quadrat was isolated and its geometry kept it at known distance from the ground. All other things being equal, the photogrammetry processing steps were the same.

\subsubsection{Photogrammetry Processing}

For each mission and its set of images, we created a new photogrammetry project in Pix4Dmapper (Pix4D S.A., Prilly, Switzerland). Pix4D was selected as it was a photogrammetry platform that has been used in many of the previously cited research projects $[13,14,25-27,29,31]$. It is based on the computer vision techniques of $[34,35]$ and implements various algorithms described in [36-38] to carry out the photogrammetry process. The GNSS coordinates, coordinate system, and camera model were automatically detected from the metadata associated with each image file. We operated in the World Geodetic System 1984 (EGM 96 Geoid) with a camera model code of FC6310_8.8_5472x3648(RGB). The images used for a single model were loaded and the processing template "3D Model", which set several program options, was chosen (Table 3). The images' locations and layout were verified in map view before adding the GCPs. 
Table 3. Processing options set in Pix4Dmapper during 3D canopy model creation.

\begin{tabular}{lcc}
\hline & Processing Step & Option \\
\hline 1. & Initial Processing & Keypoints Images Scale = Full \\
2. & Point Cloud Mesh & Export $=$ LAS (a file format for saving point clouds) \\
& Resolution = Automatic; \\
3. & $\begin{array}{c}\text { DSM (Digital Surface Model) }, \\
\text { Orthomosaic, and Index. }\end{array}$ & Use Noise Filtering (box is checked); \\
& Use Surface Smoothing (box is checked)-Type = Sharp. \\
\hline
\end{tabular}

Utilizing the GCP/MTP Manager, the GCPs for the given field were imported and the Basic Editor tool was used to tag each GCP on 3-10 separate images. Once complete, the rough locations of all the GCPs were verified in the map view and compared with field notes to ensure the point had been marked correctly. Finally, we ran only the initial processing step. The initial processing step could be completed rapidly while the final two steps of model generation would take approximately one hour per 100 images. Verifying the model after the initial processing enabled quick identification and resolution of any errors detected at this stage. If failures were noted or the model did not pass the initial assessment detailed in the next section, the initial processing step was repeated. After processing each flight to create individual models, all the images from all three flights over a field on a single day were processed together to create one final model (the Combined model).

\subsubsection{Model Assessment}

The Root Mean Square Error (RMSE) of the GCPs was a local indicator of how well Pix4Dmapper fits the model to the GCPs. It represented the consistency between the geolocation measured in the field and the geolocation Pix4Dmapper estimates when processing the model. The goal was to minimize this value. In order to calculate RMSE, the error between the actual location of each GCP and its location in the model was divided into directional errors (X, Y, and Z components). All of the directional errors for all the GCPs in a model were combined through the root-mean-square calculation to provide a RMSE for each direction [39]. In order to provide a single value for a model, the three directional RMSE values were averaged to create the Model RMSE. A Model RMSE of greater than $20 \mathrm{~cm}$ after the initial processing step indicated that this step had failed and that the project should be recreated from the beginning. These failed models had generated a point cloud, but it was corrupt and contained strange artifacts (e.g. Figure 1). Model RMSE varied for the final 3D models but in all cases successful models had values much lower than $20 \mathrm{~cm}$.

The ground sampling distance (GSD) was a measure of the spatial resolution of the 3D model and was defined as the distance between two neighboring pixels. A larger value indicates a model with less detail. Higher flights at higher altitudes generally have higher GSD values. The GSD is calculated separately for every pair of neighboring pixels in the model. In order to provide a GSD value for the entire model, all of the individual GSDs in the model were averaged together to produce the Model GSD. The final variable, which is the camera optimization, is the percentage difference between the initial and optimized parameters of the camera.

After processing each flight with GCPs and creating a final 3D canopy model, we checked the model output. In the case of a completely failed model, Pix4DMapper would provide an error stating that the process failed to produce any models. The model creation process is a stochastic matching process and so it is affected by initial conditions. It can potentially be trapped in the local minima of the optimization function. Simply repeating the processing steps provided new initial conditions and often corrected issues within this step. Once a model had completed processing without errors, the final Model RMSE, Model GSD, and camera calibration difference were recorded.

\subsubsection{Yield Estimation Using the 3D Canopy Models}

For all the photogrammetry models, the 3D canopy inside the quadrats was isolated. The point cloud from this canopy was processed following the procedure in [13] and the 
yield estimation models developed in [13] were applied to produce yield estimates in each quadrat. In [13], yield models were developed using 2-variables, which were the mean and standard deviation of the canopy heights, and 3-variables, which also added the average maturity level of the field on that day to the mean and standard deviation of the canopy heights that were used in the 2-variable model. Both of these models are Gaussian Random Process models with rational quadratic kernel functions. The 2-variable and 3-variable models were applied to each of the quadrat canopies. The estimates from these models were then compared with the actual yield obtained by hand harvesting the quadrat. For each set of flight parameters, the RMSE and $R^{2}$ value for the relationship between the estimated and actual yield was calculated.

\section{Results}

\subsection{D Model Creation}

The image sets from the 24 flights (two fields on four dates while using three different flight parameters) were processed individually and combined as described in the methods section. This resulted in 32 unique models of the alfalfa canopy, which are summarized in Table 4. Not all models completed the processing stage on the initial attempt. Three models were processed twice and one model was processed three times before successfully generating a 3D canopy as is noted in Table 4. In the end, Pix4D was able to generate 3D canopy models for each one by following the procedures outlined above and none of them possessed obvious errors such as multiple ground planes, strange artifacts, or discontinuities.

Table 4. The properties of the 32 models that were processed in this study.

\begin{tabular}{|c|c|c|c|c|c|c|}
\hline $\begin{array}{c}\text { Date } \\
\text { (dd/mm/yyyy) }\end{array}$ & Field & $\begin{array}{c}\text { Flight Parameters } \\
\text { (Height (m)-Gimbal } \\
\text { Angle) }\end{array}$ & $\begin{array}{c}\text { Field Scan } \\
\text { (Full/Partial) }\end{array}$ & $\begin{array}{l}\text { Model RMSE } \\
\text { (cm) }\end{array}$ & $\begin{array}{c}\text { Camera } \\
\text { Calibration } \\
\text { Difference (\%) }\end{array}$ & $\begin{array}{l}\text { Model GSD } \\
(\mathrm{cm})\end{array}$ \\
\hline \multirow{8}{*}{$17 / 05 / 2019$} & Field 1 & $30-90^{\circ}$ & Partial & 0.50 & $4.44 \%$ & 0.79 \\
\hline & Field 1 & $50-75^{\circ}$ & Partial & 1.00 & $2.55 \%$ & 1.44 \\
\hline & Field $1^{\mathrm{c}}$ & $50-90^{\circ}$ & Full & 1.00 & $11.3 \%$ & 1.38 \\
\hline & Field 1 & Combined & Combined & 0.50 & $0.70 \%$ & 1.35 \\
\hline & Field $2^{c}$ & $30-90^{\circ}$ & Partial & 1.40 & $85.4 \%$ a & 0.79 \\
\hline & Field 2 & $50-75^{\circ}$ & Full & 1.90 & $0.30 \%$ & 1.41 \\
\hline & Field 2 & $50-90^{\circ}$ & Full & 2.10 & $0.45 \%$ & 1.36 \\
\hline & Field 2 & Combined & Combined & 1.40 & $0.25 \%$ & 1.23 \\
\hline \multirow{8}{*}{$21 / 05 / 2019$} & Field 1 & $30-90^{\circ}$ & Partial & 1.30 & $11.3 \%$ & 0.79 \\
\hline & Field 1 & $50-75^{\circ}$ & Partial & 1.60 & $3.00 \%$ & 1.39 \\
\hline & Field 1 & $50-90^{\circ}$ & Partial & 0.60 & $8.55 \%$ & 1.28 \\
\hline & Field 1 & Combined & Combined & 0.80 & $0.99 \%$ & 0.81 \\
\hline & Field 2 & $30-90^{\circ}$ & Partial & 1.50 & $4.55 \%$ & 0.77 \\
\hline & Field 2 & $50-75^{\circ}$ & Full & 1.70 & $1.09 \%$ & 1.37 \\
\hline & Field 2 & $50-90^{\circ}$ & Full & 1.70 & $0.67 \%$ & 1.34 \\
\hline & Field 2 & Combined & Combined & 1.30 & $0.13 \%$ & 1.27 \\
\hline \multirow{8}{*}{$28 / 05 / 2019$} & Field 1 & $30-90^{\circ}$ & Partial & 2.50 & $14.1 \%$ & 0.74 \\
\hline & Field 1 & $50-75^{\circ}$ & Partial & 2.00 & $4.62 \%$ & 1.38 \\
\hline & Field 1 & $50-90^{\circ}$ & Partial & 2.40 & $5.49 \%$ & 1.35 \\
\hline & Field 1 & Combined & Combined & 2.20 & $0.07 \%$ & 0.77 \\
\hline & Field $2^{c}$ & $30-90^{\circ}$ & Partial & $13.1^{\mathrm{b}}$ & $14.3 \%$ & 0.79 \\
\hline & Field $2 \mathrm{~d}$ & $50-75^{\circ}$ & Full & 2.20 & $1.56 \%$ & 1.46 \\
\hline & Field 2 & $50-90^{\circ}$ & Full & 5.70 & $0.56 \%$ & 1.38 \\
\hline & Field 2 & Combined & Combined & 5.20 & $0.21 \%$ & 1.31 \\
\hline \multirow{8}{*}{ 04/06/2019 } & Field 1 & $30-90^{\circ}$ & Partial & 1.60 & $12.5 \%$ & 0.76 \\
\hline & Field 1 & $50-75^{\circ}$ & Partial & 1.80 & $2.92 \%$ & 1.42 \\
\hline & Field 1 & $50-90^{\circ}$ & Partial & 2.20 & $5.49 \%$ & 1.36 \\
\hline & Field 1 & Combined & Combined & 1.90 & $0.13 \%$ & 0.79 \\
\hline & Field 2 & $30-90^{\circ}$ & Partial & 2.30 & $14.2 \%$ & 0.75 \\
\hline & Field 2 & $50-75^{\circ}$ & Full & 2.20 & $1.08 \%$ & 1.40 \\
\hline & Field 2 & $50-90^{\circ}$ & Full & 2.20 & $1.92 \%$ & 1.33 \\
\hline & Field 2 & Combined & Combined & 2.00 & $0.10 \%$ & 1.25 \\
\hline
\end{tabular}

${ }^{a}$ Model had an unusually large camera calibration difference and was removed from further processing (entry italicized). ${ }^{b}$ Model had an unusually large Model RMSE and was removed from further processing (entry italicized). ${ }^{\mathrm{c}}$ Model was processed twice. These are the results for the final processing run. ${ }^{\mathrm{d}}$ Model was processed three times. These are the results for the final processing run. 
Based on the extreme outliers in Model RMSE, camera calibration difference, and Model GSD, two of the 32 models were judged not acceptable. One model had an unusually large camera calibration difference of $85.4 \%$, which was 38 times the median value of $2.24 \%$ and the other had an unusually large Model RMSE of $13.1 \mathrm{~cm}$, which was seven times greater than the median value of $1.91 \mathrm{~cm}$. These two models were considered failed attempts. They were removed from further processing and not considered in any further results. Note that these models were two of the four that had required additional processing attempts to even create a 3D model in the first place. While the other two models that had issues during initial processing did eventually result in acceptable models, the final outputs of these two attempts were not acceptable. Thus, of the 32 models that were attempted, 30 of them produced acceptable models.

The values in Table 4 precisely describe the detail of the models, but images of the models are also useful in understanding the model detail. Examples of a section of the model created using the images captured with the $30-90^{\circ}$ flight parameters on 4 June 2019 in Field 1 are shown in Figures 4-6. The images show that the models captured gaps in canopy coverage and details such as the wheeled traffic effects from a spray application two weeks prior.

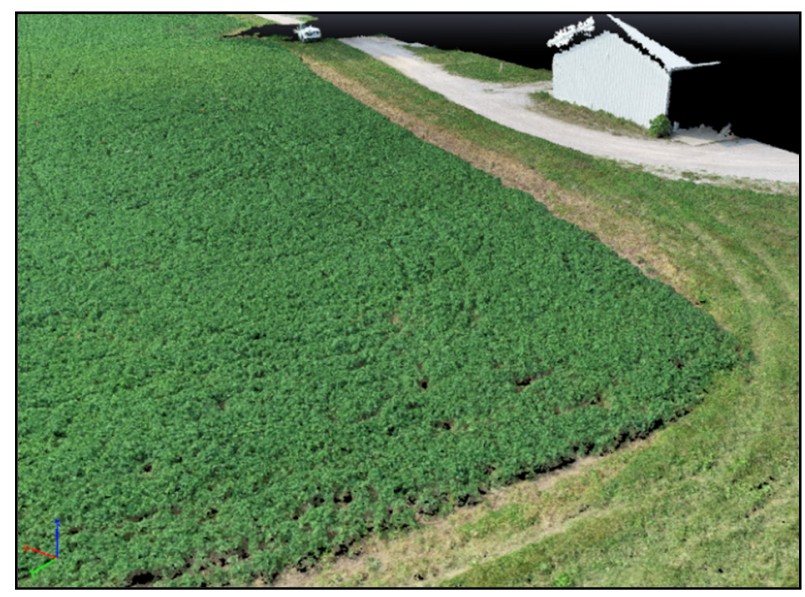

Figure 4. An isometric top view of a portion of a fully processed alfalfa model of field 1 flown on 4 June 2019 using $30-90^{\circ}$ flight parameters. Only part of the nearby barn is modeled as the flights only recorded one side of the building.

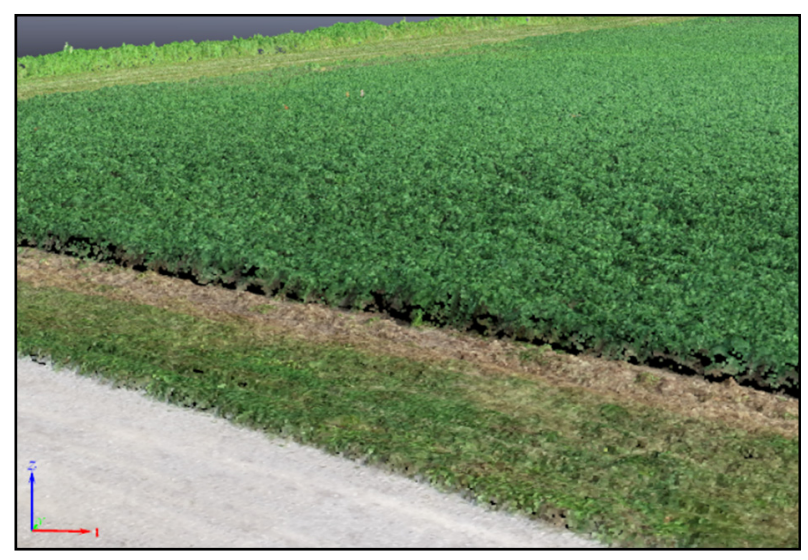

Figure 5. A side view of the alfalfa canopy in Field 1 from a portion of a fully processed model flown on 4 June 2019 using $30-90^{\circ}$ flight parameters. Although the UAV did not take pictures from this angle and this close to the ground, the photogrammetry process captured the transition from the short grass bordering the field to the taller alfalfa plants. 


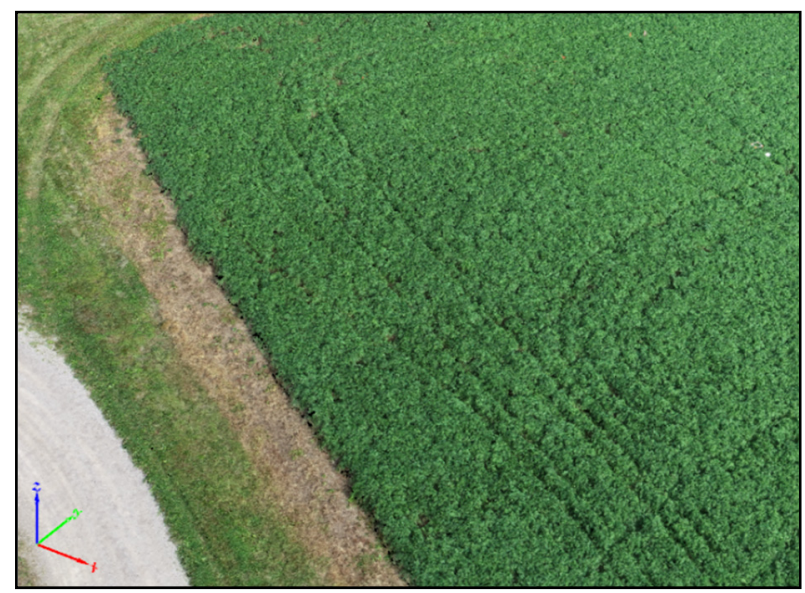

Figure 6. An aerial view of the alfalfa canopy in field 1 and tracks from wheeled traffic on a portion of a fully processed model flown on 4 June 2019 using $30-90^{\circ}$ flight parameters.

The results from the individual models were compiled by flight parameters used in the flight to capture the model data (Table 5). The largest effect of the flight parameters was on the GSD. The flights at an altitude of $30 \mathrm{~m}$ had a much lower mean Model GSD compared to the flights at $50 \mathrm{~m}$, as would be expected with models based on images taken at different altitudes. This corresponds to finer detail in the models from the flights at $30 \mathrm{~m}$. There was also little variation (low standard deviation) in the GSD between models created using a given flight parameter. For all models created using the $30-90^{\circ}$ flight parameters, the GSD was always less than $1 \mathrm{~cm}$. For models created using $50-75^{\circ}$ and $50-90^{\circ}$ flight parameters, the GSD was always below $1.5 \mathrm{~cm}$.

Table 5. Model GSD by flight parameters used in flights (including both fields on all four sampling days).

\begin{tabular}{ccccc}
\hline Flight Parameters & \multicolumn{4}{c}{ Model GSD (cm) } \\
\cline { 2 - 5 } (Height (m)-Gimbal Angle) & Min. & Max. & Mean & Std. Dev \\
\hline $30-90^{\circ}$ & 0.740 & 0.790 & 0.767 & 0.021 \\
$50-75^{\circ}$ & 1.37 & 1.46 & 1.41 & 0.030 \\
$50-90^{\circ}$ & 1.28 & 1.38 & 1.35 & 0.032 \\
Combined & 0.770 & 1.35 & 1.09 & 0.257 \\
\hline
\end{tabular}

There were fewer significant differences in the Model RMSE values (Table 6). While the models created using the images from the flights at $30 \mathrm{~m}$ did have lower mean Model RMSE, there were no significant differences (using $\alpha=0.05$ ) between the Model RMSE values based on flight parameters. Maximum RMSE values (from acceptable models) were as high as $5.7 \mathrm{~cm}$, but such high values were rare. Of the 30 acceptable models, 28 models had Model RMSE values less than $2.5 \mathrm{~cm}$.

Table 6. Model RMS Error by flight parameter used in flights (including both fields on all four sampling days).

\begin{tabular}{ccccc}
\hline Flight Parameters & \multicolumn{4}{c}{ Model RMS Error (cm) } \\
\cline { 2 - 5 } (Height (m)-Gimbal Angle) & Min. & Max. & Mean & Std. Dev \\
\hline $30-90^{\circ}$ & 0.500 & 2.50 & 1.62 & 0.722 \\
$50-75^{\circ}$ & 1.00 & 2.20 & 1.80 & 0.389 \\
$50-90^{\circ}$ & 0.600 & 5.70 & 2.24 & 1.54 \\
Combined & 0.500 & 5.20 & 1.91 & 1.45 \\
\hline
\end{tabular}

Interestingly, the combination models performed worse than models based on images taken only at $30 \mathrm{~m}$. The additional images from the two flights using the $50 \mathrm{~m}$ flight 
parameters did not improve the model creation process. They only appeared to increase additional processing time.

\subsection{Yield Estimation}

There were 10 sampling quadrats per field on each of the four sampling days. This corresponds to a total of 80 samples for each flight parameter. However, not all samples created 3D canopy point clouds that could be used in the yield estimation model. The most common issue was that the highly visible geometric structure of the sampling quadrat would create canopy distortions inside the sampling region and the point cloud processing steps used to estimate yield would fail. Of the 80 possible quadrat samples, there were $75,34,34,28$, and 72 usable samples for the yield estimation model from the Quadrat Only, $30-90^{\circ}, 50-90^{\circ}, 50-75^{\circ}$, and the Combination model, respectively. The Quadrat Only and Combination models had more views of the quadrats from different angles, which appeared to assist those models by reducing distortions from the quadrats. In actual field usage, the sampling quadrats should not be an issue since they are not normally present during alfalfa production. Future work with complete field imagery at $30 \mathrm{~m}$ and $50 \mathrm{~m}$ elevations will need to use different sampling quadrats to eliminate the introduction of artificial structures to the field canopy.

When the 3D canopy models were combined with the yield estimation models presented in [13], the yield estimation accuracy mostly aligned (Table 7) with the previously discussed canopy model accuracy represented by the Model RMS Error. The $50-75^{\circ}$ and the $30-90^{\circ}$ FP did better than the $50-90^{\circ}$ and the combined models. However, for yield estimation, the $50-75^{\circ}$ FP had the lowest error and the highest $R^{2}$ values when used to predict the yield within the test quadrats. The next best set of flight parameters that covered the entire field was the $30-90^{\circ}$ FP. The combined FP created the worst yield estimates. This set of data also included the Quadrat Only FP which consisted of individual canopy models created for each yield sampling quadrat at a height of approximately 10 meters with varying non-nadir gimbal angles. Although the Quadrat Only FP had the lowest flight altitude and had independent 3D canopies for each quadrat, it was only about as accurate as the $30-90^{\circ}$ FP. The error rates and $R^{2}$ values are different when the canopies are used in the 2-variable and 3-variable models, but the trends remain similar with both approaches for estimating yield: $50-75^{\circ} \mathrm{FP}$ produced the best estimates and the Combined FP produced the worst.

Table 7. Yield estimation accuracy using the 3D canopy models from different flight parameters.

\begin{tabular}{|c|c|c|c|c|c|c|}
\hline \multirow{2}{*}{$\begin{array}{c}\text { Flight Parameters } \\
\text { (Height (m)-Gimbal } \\
\text { Angle) }\end{array}$} & \multicolumn{2}{|c|}{$\begin{array}{c}\text { 3-Variable } \\
\text { Model }\end{array}$} & \multicolumn{2}{|c|}{$\begin{array}{c}\text { 2-Variable } \\
\text { Model }\end{array}$} & \multicolumn{2}{|c|}{$\begin{array}{c}\text { Average } \\
\text { (Both Models) }\end{array}$} \\
\hline & $\begin{array}{c}\text { RMSE } \\
\left(\mathrm{kg} \mathrm{ha}^{-1}\right)^{\mathrm{a}}\end{array}$ & $\mathbf{R}^{2}$ & $\begin{array}{c}\text { RMSE } \\
\left(\mathrm{kg} \mathrm{ha}^{-1}\right)^{a}\end{array}$ & $\mathbf{R}^{2}$ & $\begin{array}{c}\text { RMSE } \\
\left(\mathrm{kg} \mathrm{ha}^{-1}\right)^{a}\end{array}$ & $\mathbf{R}^{2}$ \\
\hline Quadrat Only & 907 & 0.71 & 821 & 0.60 & 864 & 0.65 \\
\hline $30-90^{\circ}$ & 780 & 0.68 & 897 & 0.30 & 838 & 0.49 \\
\hline $50-75^{\circ}$ & 490 & 0.87 & 354 & 0.84 & 422 & 0.85 \\
\hline $50-90^{\circ}$ & 1045 & 0.55 & 966 & 0.35 & 1005 & 0.45 \\
\hline Combined & 1298 & 0.53 & 1353 & 0.47 & 1325 & 0.50 \\
\hline Average & 904 & 0.67 & 878 & 0.51 & 891 & 0.59 \\
\hline
\end{tabular}

a Maximum yield was $3800 \mathrm{~kg} \mathrm{ha}^{-1}$.

The 2-variable and 3-variable models were created using individual flights and 3D models for each sampling quadrat in a manner that is most similar to the Quadrat Only FP presented in Table 7. In [13], the 2-variable and the 3-varible model were found to predict yields with RSME $/ \mathrm{R}^{2}$ of $799 \mathrm{~kg} \mathrm{ha}^{-1} / 0.63$ and $734 \mathrm{~kg} \mathrm{ha}^{-1} / 0.69$, respectively. These are similar to the values obtained with the Quadrat Only FP parameters. This set of experiments was conducted in different fields in a different growing year and so both yield estimation models are consistent even with the changes in varieties, fields, and weather 
conditions. As in [13], the 3-variable model performed better than the 2-variable model with lower RMS Error and higher $\mathrm{R}^{2}$ values when considering the average of all flight methods. However, for the $30-90^{\circ}$ and $50-90^{\circ}$ flight parameters with the 2-variable model, the $\mathrm{R}^{2}$ values fell below 0.4 and so the 2 -variable model does not work well with those flight parameters. Interestingly, using the $50-75^{\circ} \mathrm{FP}$ produced better results than the high-resolution models from the Quadrat Only canopies. The RMSE and $\mathrm{R}^{2}$ values for yield estimates with the $50-75^{\circ} \mathrm{FP}$ were even better than those obtained when initially creating the models.

\section{Discussion}

While $94 \%$ of the 32 attempted models were created successfully, the two failed models demonstrate that these flight parameters are not foolproof. If a model is being used for mission critical decision making and a usable model is crucial, multiple flights using different flight parameters may be warranted. In cases where a model failed in this study, the models based on a different set of flight parameters over the same field at the same time were always able to create a successful model. The canopies captured during this project include entire whole alfalfa forage growth cycle. They start at seven days after cutting when regrowth was just beginning. The final canopy was measured 28 days after cutting when the crop was, again, ready for harvest. Therefore, these parameters appear acceptable for utilization in modeling the canopy during the entire growth cycle of the alfalfa forage.

The models produced with the $30-90^{\circ} \mathrm{FP}$ were more detailed as determined by the GSD, but they were not more accurate based on the lack of significant differences in Model RMSE between the different flight parameters. These models were also less accurate when used to predict yield. We also found little benefit from combining images from flights with multiple parameters. While the combined models did appear to have a denser point cloud than many of the other models, the additional processing time, minimal difference in model accuracy parameters, and the lower ability to predict alfalfa yield when used with the alfalfa yield prediction models suggests that this approach is actually detrimental to the usefulness of a model.

We suggest using the $50-75^{\circ}$ parameters for the creation of alfalfa canopies with the 3 -variable model for predicting yield. Lower altitudes required much longer flight and processing times and the models were not always acceptable after processing. In comparing the gimbal angles at $50 \mathrm{~m}$, the $75^{\circ}$ gimbal angle provided more consistent Model RMSEs that were always less than $2.2 \mathrm{~cm}$, unlike the $90^{\circ}$ gimbal angle which had a maximum of $5.7 \mathrm{~cm}$. The tests, when using the different flight parameters to predict alfalfa yield, further strengthen this suggestion. The $50-75^{\circ}$ parameters were clearly the best for this particular use. The 3-variable model was more consistent across flight parameters, which could be useful for real world applications where field elevation changes may make it difficult to maintain an exact flight height above the ground. While the 2-variable model with the $50-75^{\circ}$ parameters had slightly lower RMSE than the 3-variable model, its $R^{2}$ with all flight parameters was always lower than the 3 -variable model. In certain situations, the $\mathrm{R}^{2}$ could be as low as $0.30\left(30-90^{\circ}\right)$ or $0.35\left(50-90^{\circ}\right)$. In our previous study, the RMSE followed the trend of the $\mathrm{R}^{2}$ values with the 3-variable model providing better results than the 2-variable model. For the sake of consistency, the 3-variable model appears to be the better option. Further testing would be necessary to see if flights at slightly higher altitudes may also provide acceptable accuracy levels, but based on the results of other studies we should see deteriorating accuracies and detail as we increase in height $[27,28,30,31]$.

\section{Comparisons with Other Studies}

While other studies aimed at estimating biomass or crop yield did not report the effect of varying flight heights, they flew missions at similar heights between $30 \mathrm{~m}$ and $50 \mathrm{~m}$ above ground level. However, these studies all appeared to use cameras with a $90^{\circ}$ gimbal angle. The results of our study indicate that switching to a $70^{\circ}$ gimbal angle has the potential to improve crop height models and, thus, their biomass or yield estimation results. 
A major difference between our study and the other photogrammetry studies is our focus on the ability to reliably create an acceptable model and consistently estimate alfalfa yield correctly. Our study performed multiple repetitions of flights using each flight parameter on different days and on multiple fields. In commercial alfalfa production, farmers must periodically assess the crop to determine appropriate harvest time as well as other production decisions such as when to spray various chemicals. The crop is constantly developing and timely information is critical in the production decision making process. In this project, we followed this periodic monitoring requirement and flew every seven days exactly. Other studies had different goals and many based their analysis on a single set of flights. Since they were not flying on a set schedule, they could have waited for perfect flight capture conditions (e.g. no wind) and repeated any flights that provided unacceptable results after photogrammetry processing. It is also possible that the fields and environments targeted in these studies have enough natural variation that model failure is not an issue. Given the inquiries into our methods and our own difficulty in initially identifying appropriate flight parameters, consistency and reliability are important additional factors, which this study has addressed.

\section{Conclusions}

Based on this study, we suggest the utilization of a set of flight parameters for creating $3 \mathrm{D}$ models of alfalfa canopies. Following the procedures provided here, producers and researchers can be confident that they will consistently be able to generate a 3D canopy model with a single coverage flight based on our acceptable model creation rate of $94 \%$. Furthermore, this remains true for all of the alfalfa growth stages from initial regrowth from sparse crowns to a fully closed canopy. In the cases where one of our canopy models was not acceptable, our other trials on that day and in that field did provide acceptable models. If a successful 3D canopy model is absolutely required, it is suggested that a second flight with different image capture points be performed. Model detail (measured by GSD) varied by flight altitude and gimbal angle between the means of $0.767 \mathrm{~cm}$ for the $30-90^{\circ}$ flight parameters and $1.41 \mathrm{~cm}$ with the $50-75^{\circ}$ flight parameters. However, the geolocation error (measured by Model RMSE) was similar for the different flight parameters with an overall mean of $1.91 \mathrm{~cm}$. When these canopies were used with alfalfa prediction models, the $50-75^{\circ}$ flight parameter clearly provided the best estimate of alfalfa yield. Given the lower flight durations and processing times as well as increased consistency in geolocation accuracy, most users should opt for flights with a $50 \mathrm{~m}$ altitude and $75^{\circ}$ gimbal angle. If the target application for the $3 \mathrm{D}$ canopy is alfalfa yield estimation, then the $50-75^{\circ}$ flight parameter is strongly suggested.

Author Contributions: Conceptualization, J.D. and J.J.; methodology, C.M., J.D., J.J., and S.T.S.; formal analysis, S.T.S. and C.M.; investigation, C.M. and J.D.; resources, J.D.; data curation, C.M. and S.T.S.; writing—original draft preparation, C.M.; writing—review and editing, J.D., S.T.S., and J.J.; visualization, C.M. and S.T.S.; supervision, J.D.; project administration, J.D.; funding acquisition, J.D. and J.J. All authors have read and agreed to the published version of the manuscript.

Funding: This work is supported by the Alfalfa and Forage Research Program grant no. 2016-7000525648 / project accession no. 1010223 from the USDA National Institute of Food and Agriculture.

Data Availability Statement: Upon acceptance of this manuscript, we will work with the editor to determine the appropriate public posting location for the data from this project. The raw images are approximately $50 \mathrm{~GB}$ and the photogrammetry models are also very large, which limits posting locations.

Conflicts of Interest: The authors declare no conflict of interest. The funders had no role in the design of the study; in the collection, analyses, or interpretation of data; in the writing of the manuscript or in the decision to publish the results. 


\section{References}

1. Nelson, B. Alfalfa Remains Country's 3rd Most Valuable Field Crop; National Alfalfa \& Forage Alliance: St. Paul, MN, USA, 2019.

2. NASS. Crop Values 2017 Summary; United State Department of Agriculture, National Agricultural Statistics Service: Washington, DC, USA, 2018.

3. Lamb, J.F.S.; Sheaffer, C.C.; Samac, D.A. Population Density and Harvest Maturity Effects on Leaf and Stem Yield in Alfalfa. Agron. J. 2003, 95, 635-641. [CrossRef]

4. Ball, D.M.; Collins, M.; Lacefield, G.D.; Martin, N.P.; Mertens, D.A.; Olson, K.E.; Putnam, D.H.; Undersander, D.J.; Wolf, M.W. Understanding Forage Quality; American Farm Bureau Federation Publication: Park Ridge, IL, USA, 2001 ; Volume 1.

5. Saha, U.K.; Sonon, L.S.; Hancock, D.W.; Hill, N.S.; Stewart, L.; Heusner, G.L.; Kissel, D.E. Common Terms Used in Animal Feeding and Nutrition; University of Georgia, College of Agricultural and Environmental Sciences: Athens, GA, USA, 2017.

6. Undersander, D.; Hall, M.H.; Vassalotti, P.; Cosgrove, D. Alfalfa Germination \& Growth; University of Wisconsin-Extension Cooperative Extension: Madison, WI, USA, 2011; p. 18.

7. Ball, D.M.; Hoveland, C.S.; Lacefield, G.D. Southern Forages; Potash \& Phosphate Institute, Foundation for Agronomic Research: Atlanta, GR, USA, 1991; ISBN 978-0-9629598-1-3.

8. Hancock, D.W.; Buntin, G.D.; Ely, L.O.; Lacy, R.C.; Heusner, G.L.; Stewart, R.L. Alfalfa Management in Georgia; University of Georgia, College of Agricultural and Environmental Sciences: Athens, GA, USA, 2009.

9. Undersander, D.; Cosgrove, D.; Cullen, E.; Grau, C.; Rice, M.E.; Renz, M.; Sheaffer, C.C.; Shewmaker, G.; Sulc, M. Alfalfa Management Guide; American Society of Agronomy: Madison, WI, USA, 2011; ISBN 0-89118-179-2.

10. Hintz, R.W.; Albrecht, K.A. Prediction of Alfalfa Chemical Composition from Maturity and Plant Morphology. Crop Sci. 1991, 31. [CrossRef]

11. Lang, B. Estimate First Crop Pre-Harvest Alfalfa Quality in the Field Using PEAQ; Iowa State University Extension and Outreach Publication: Ames, IA, USA, 2017; pp. 1-2.

12. Mueller, S.C.; Teuber, L.R. Alfalfa Growth and Development. In Irrigated Alfalfa Management for Mediterranean and Desert Zones; Summers, C.G., Putnam, D.H., Eds.; University of California Alfalfa \& Forage Systems Workgroup: Davis, CA, USA, 2007.

13. Dvorak, J.S.; Pampolini, L.F.; Jackson, J.J.; Seyyedhasani, H.; Sama, M.P.; Goff, B. Predicting Quality and Yield of Growing Alfalfa from a UAV. Trans. ASABE 2021, 64, 1. [CrossRef]

14. Brodbeck, C.; Sikora, E.; Delaney, D.; Pate, G.; Johnson, J. Using Unmanned Aircraft Systems for Early Detection of Soybean Diseases; Cambridge University Press: Edinburgh, UK, July 2017; Volume 8, pp. 802-806.

15. Vanegas, F.; Bratanov, D.; Powell, K.; Weiss, J.; Gonzalez, F. A Novel Methodology for Improving Plant Pest Surveillance in Vineyards and Crops Using UAV-Based Hyperspectral and Spatial Data. Sensors 2018, 18, 260. [CrossRef]

16. Chang, A.; Jung, J.; Maeda, M.M.; Landivar, J. Crop Height Monitoring with Digital Imagery from Unmanned Aerial System (UAS). Comput. Electron. Agric. 2017, 141, 232-237. [CrossRef]

17. Enciso, J.; Avila, C.A.; Jung, J.; Elsayed-Farag, S.; Chang, A.; Yeom, J.; Landivar, J.; Maeda, M.; Chavez, J.C. Validation of Agronomic UAV and Field Measurements for Tomato Varieties. Comput. Electron. Agric. 2019, 158, 278-283. [CrossRef]

18. Madec, S.; Baret, F.; de Solan, B.; Thomas, S.; Dutartre, D.; Jezequel, S.; Hemmerlé, M.; Colombeau, G.; Comar, A. HighThroughput Phenotyping of Plant Height: Comparing Unmanned Aerial Vehicles and Ground LiDAR Estimates. Front. Plant Sci. 2017, 8, 2002. [CrossRef] [PubMed]

19. Watanabe, K.; Guo, W.; Arai, K.; Takanashi, H.; Kajiya-Kanegae, H.; Kobayashi, M.; Yano, K.; Tokunaga, T.; Fujiwara, T.; Tsutsumi, N.; et al. High-Throughput Phenotyping of Sorghum Plant Height Using an Unmanned Aerial Vehicle and Its Application to Genomic Prediction Modeling. Front. Plant Sci. 2017, 8, 421. [CrossRef]

20. Feng, A.; Zhang, M.; Sudduth, K.A.; Vories, E.D.; Zhou, J. Cotton Yield Estimation from UAV-Based Plant Height. Trans. ASABE 2019, 62, 393-404. [CrossRef]

21. Huang, Y.; Brand, H.J.; Sui, R.; Thomson, S.J.; Furukawa, T.; Ebelhar, M.W. Cotton Yield Estimation Using Very High-Resolution Digital Images Acquired with a Low-Cost Small Unmanned Aerial Vehicle. Trans. ASABE 2016, 59, 1563-1574. [CrossRef]

22. Bendig, J.; Bolten, A.; Bennertz, S.; Broscheit, J.; Eichfuss, S.; Bareth, G. Estimating Biomass of Barley Using Crop Surface Models (CSMs) Derived from UAV-Based RGB Imaging. Remote Sens. 2014, 6, 10395-10412. [CrossRef]

23. Lu, N.; Zhou, J.; Han, Z.; Li, D.; Cao, Q.; Yao, X.; Tian, Y.; Zhu, Y.; Cao, W.; Cheng, T. Improved Estimation of Aboveground Biomass in Wheat from RGB Imagery and Point Cloud Data Acquired with a Low-Cost Unmanned Aerial Vehicle System. Plant Methods 2019, 15, 17. [CrossRef]

24. Yue, J.; Yang, G.; Li, C.; Li, Z.; Wang, Y.; Feng, H.; Xu, B. Estimation of Winter Wheat Above-Ground Biomass Using Unmanned Aerial Vehicle-Based Snapshot Hyperspectral Sensor and Crop Height Improved Models. Remote Sens. 2017, 9, 708. [CrossRef]

25. Shi, Y.; Thomasson, J.A.; Murray, S.C.; Pugh, N.A.; Rooney, W.L.; Shafian, S.; Rajan, N.; Rouze, G.; Morgan, C.L.S.; Neely, H.L.; et al. Unmanned Aerial Vehicles for High-Throughput Phenotyping and Agronomic Research. PLoS ONE 2016, 11, e0159781. [CrossRef] [PubMed]

26. Gauci, A.A.; Brodbeck, C.J.; Poncet, A.M.; Knappenberger, T. Assessing the Geospatial Accuracy of Aerial Imagery Collected with Various UAS Platforms. Trans. ASABE 2018, 61, 1823-1829. [CrossRef]

27. Mesas-Carrascosa, F.-J.; Torres-Sánchez, J.; Clavero-Rumbao, I.; García-Ferrer, A.; Peña, J.-M.; Borra-Serrano, I.; López-Granados, F. Assessing Optimal Flight Parameters for Generating Accurate Multispectral Orthomosaicks by UAV to Support Site-Specific Crop Management. Remote Sens. 2015, 7, 12793-12814. [CrossRef] 
28. Seifert, E.; Seifert, S.; Vogt, H.; Drew, D.; van Aardt, J.; Kunneke, A.; Seifert, T. Influence of Drone Altitude, Image Overlap, and Optical Sensor Resolution on Multi-View Reconstruction of Forest Images. Remote Sens. 2019, 11, 1252. [CrossRef]

29. Nakano, K.; Nakano, K.; Suzuki, H.; Tamino, T.; Chikatsu, H. On Fundamental Evaluation Using Uav Imagery and 3d Modeling Software. Int. Arch. Photogramm. Remote Sens. Spat. Inf. Sci. 2016, XLI-B5, 93-97. [CrossRef]

30. Mesas-Carrascosa, F.-J.; Notario García, M.D.; Meroño de Larriva, J.E.; García-Ferrer, A. An Analysis of the Influence of Flight Parameters in the Generation of Unmanned Aerial Vehicle (UAV) Orthomosaicks to Survey Archaeological Areas. Sensors 2016, 16, 1838. [CrossRef]

31. Raczynski, R.J. Accuracy Analysis of Products Obtained from UAV-Borne Photogrammetry Influenced by Various Flight Parameters. Master's Thesis, Norwegian University of Science and Technology, Trondheim, Norway, 2017.

32. Torres-Sánchez, J.; López-Granados, F.; Borra-Serrano, I.; Peña, J.M. Assessing UAV-Collected Image Overlap Influence on Computation Time and Digital Surface Model Accuracy in Olive Orchards. Precis. Agric. 2018, 19, 115-133. [CrossRef]

33. Kalu, B.A.; Fick, G.W. Quantifying Morphological Development of Alfalfa for Studies of Herbage Quality. Crop Sci. 1981, 21, 267-271. [CrossRef]

34. Strecha, C.; von Hansen, W.; Van Gool, L.; Fua, P.; Thoennessen, U. On Benchmarking Camera Calibration and Multi-View Stereo for High Resolution Imagery. In Proceedings of the 2008 IEEE Conference on Computer Vision and Pattern Recognition, Anchorage, AK, USA, 23-28 June 2008; pp. 1-8.

35. Agarwal, S.; Furukawa, Y.; Snavely, N.; Curless, B.; Seitz, S.M.; Szeliski, R. Reconstructing Rome. Computer 2010, 43 , 40-47. [CrossRef]

36. Strecha, C.; Van Gool, L.; Fua, P. A Generative Model for True Orthorectification. In Proceedings of the International Archives of the Photogrammetry, Remote Sensing and Spatial Information Sciences Congress, Beijing, China, 3-11 July 2008.

37. Strecha; Tuytelaars; Gool, V. Dense Matching of Multiple Wide-Baseline Views. In Proceedings of the Ninth IEEE International Conference on Computer Vision, Nice, France, 13-16 October 2003; Volume 2, pp. 1194-1201.

38. Strecha, C.; Pylvänäinen, T.; Fua, P. Dynamic and Scalable Large Scale Image Reconstruction. In Proceedings of the 2010 IEEE Computer Society Conference on Computer Vision and Pattern Recognition, San Francisco, CA, USA, 13-18 June 2010; pp. 406-413.

39. Pix4D SA. How Are the GCP Errors Defined in the Quality Report. Available online: https://support.pix4d.com/hc/en-us / articles / 203604125-How-are-the-GCP-Errors-defined-in-the-Quality-Report (accessed on 15 September 2020). 